Prepared for the U.S. Department of Energy

under Contract DE-AC05-76RL01830

\title{
Gaseous Sulfate Solubility in Glass: Experimental Method
}

\section{Bliss}

November 2013

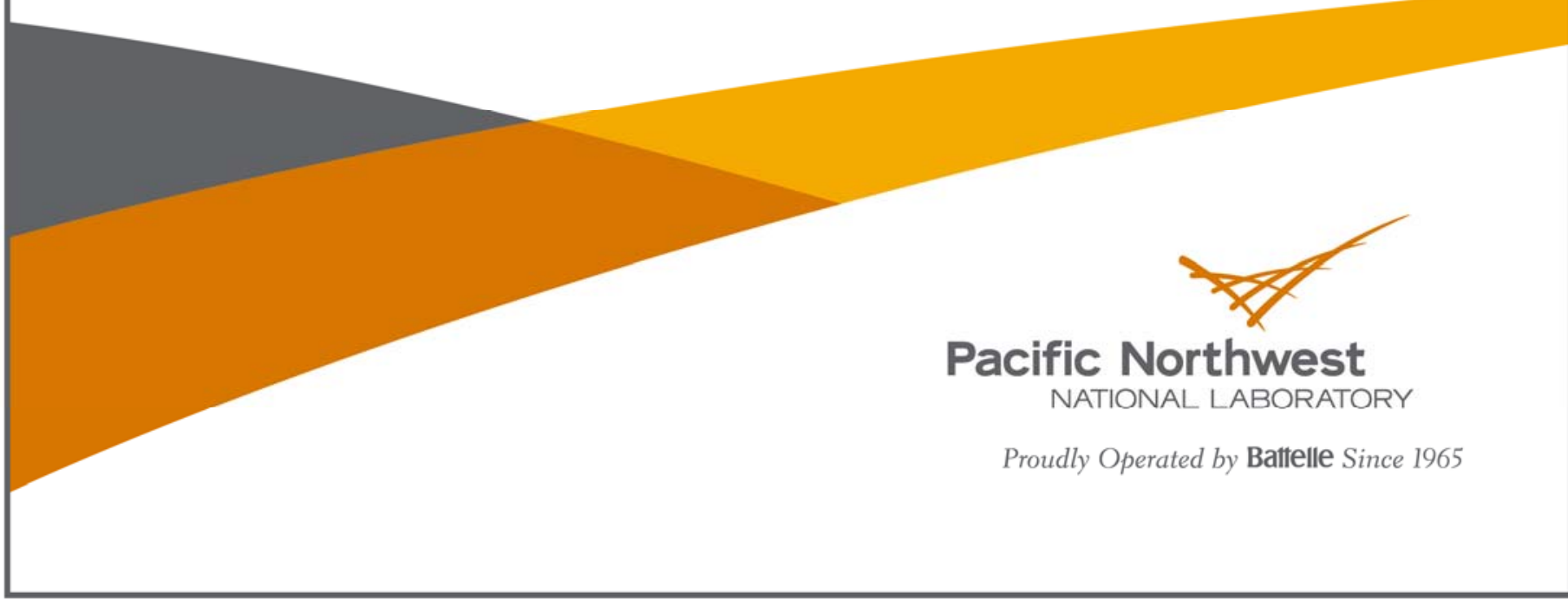




\section{DISCLAIMER}

This report was prepared as an account of work sponsored by an agency of the United States Government. Neither the United States Government nor any agency thereof, nor Battelle Memorial Institute, nor any of their employees, makes any warranty, express or implied, or assumes any legal liability or responsibility for the accuracy, completeness, or usefulness of any information, apparatus, product, or process disclosed, or represents that its use would not infringe privately owned rights. Reference herein to any specific commercial product, process, or service by trade name, trademark, manufacturer, or otherwise does not necessarily constitute or imply its endorsement, recommendation, or favoring by the United States Government or any agency thereof, or Battelle Memorial Institute. The views and opinions of authors expressed herein do not necessarily state or reflect those of the United States Government or any agency thereof.

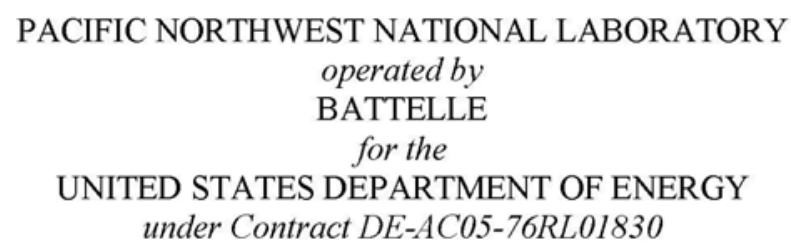

Printed in the United States of America

$$
\begin{aligned}
& \text { Available to DOE and DOE contractors from the } \\
& \text { Office of Scientific and Technical Information, } \\
& \text { P.O. Box 62, Oak Ridge, TN 37831-0062; } \\
& \text { ph: (865) 576-8401 } \\
& \text { fax: (865) 576-5728 } \\
& \text { email: reports@adonis.osti.gov }
\end{aligned}
$$

Available to the public from the National Technical Information Service 5301 Shawnee Rd., Alexandria, VA 22312 ph: (800) 553-NTIS (6847)

email: orders@ntis.gov <http://www.ntis.gov/about/form.aspx>

Online ordering: http://www.ntis.gov 


\section{Gaseous Sulfate Solubility in Glass: Experimental Method}

M Bliss

November 2013

Prepared for

the U.S. Department of Energy

under Contract DE-AC05-76RL01830

Pacific Northwest National Laboratory

Richland, Washington 99352 



\section{Executive Summary}

Sulfate solubility in glass is a key parameter in many commercial glasses and nuclear waste glasses. This report summarizes key publications specific to sulfate solubility experimental methods and the underlying physical chemistry calculations. The published methods and experimental data are used to verify the calculations in this report and are expanded to a range of current technical interest. The calculations and experimental methods described in this report will guide several experiments on sulfate solubility and saturation for the Hanford Waste Treatment Plant Enhanced Waste Glass Models effort. There are several tables of sulfate gas equilibrium values at high temperature to guide experimental gas mixing and to achieve desired $\mathrm{SO}_{3}$ levels. This report also describes the necessary equipment and best practices to perform sulfate saturation experiments for molten glasses. Results and findings will be published when experimental work is finished and this report is validated from the data obtained. 



\section{Acronyms and Abbreviations}

JANAF

LRB

MFC

NIST

PNNL

VSL
Joint Army-Navy-Air Force

Laboratory record book

Mass flow controller(s)

U.S. Department of Commerce National Institute of Standards and Technology

Pacific Northwest National Laboratory

Vitreous State Laboratory at Catholic University in Washington D.C. 



\section{Contents}

Executive Summary .........................................................................................................................................ii Acronyms and Abbreviations ...............................................................................................................

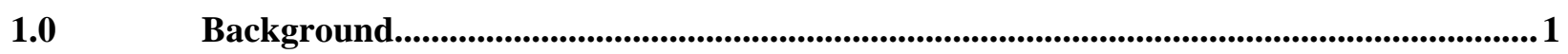

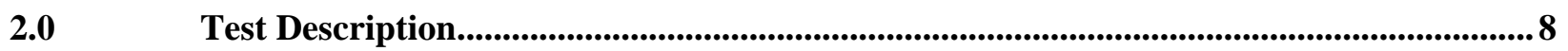

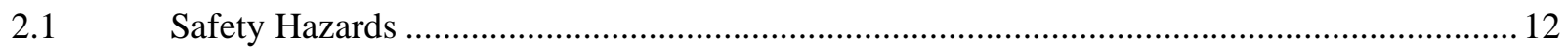

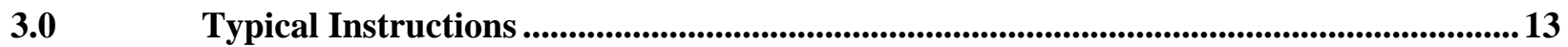

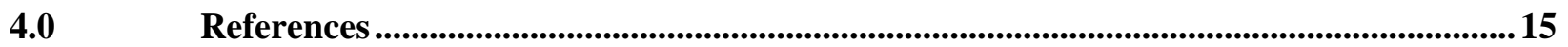

Appendix A Figure 3.1 from Kot 2006 .................................................................................................. A-1 


\section{Figures}

Figure 1: Modified Deltech furnace for sulfate solubility studies. This is a commercial furnace with an opening at the top for the insertion of the bubble tube. It meets all electrical safety standards.

Figure 2: Schematic of the gas mixing system. The MFCs are represented in red, valves in blue. The reactant gases precede the inert nitrogen in the piping. The by-pass valve is adjusted to control the bubbling rate but is designed never to be fully closed which keeps the system from over pressurizing. The MFCs are electrically connected to a MKS 247D gas controller.11

\section{Tables}

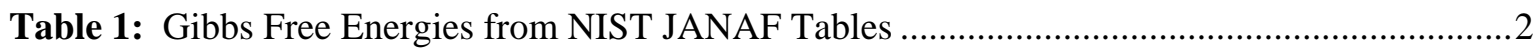

Table 2: The Calculated Free Energies and Equilibrium Constants for Reaction 1.......................3

Table 3: Calculated Partial Pressure of $\mathrm{SO}_{3}$ at Several Temperatures at Various $\mathrm{SO}_{2}$ and $\mathrm{O}_{2}$ Partial Pressures ${ }^{*}$

Table 4: Calculated Values of PO2 to Generate Desired PSO3 with Fixed PSO2 at $1150^{\circ}$ C.........6

Table 5: Calculated $\mathrm{SO}_{3}$ Values from Controllable Mixtures.......................................................

Table 6: Parts List and Specifications for Gas Mixing System.................................................11 


\subsection{Background}

This report describes the information and equipment necessary to perform and reproduce sulfate gas saturation tests in molten glasses. It summarizes the appropriate calculations and describes the necessary equipment and its operation, along with recommended operational parameters.

Sulfate has limited solubility in silicate glasses and over-saturation of sulfate forms a soluble scum layer on glass-melt surfaces. This scum layer creates a quality issue and as well as a technical one, as sulfate evolution contributes to fining of commercial glasses. Soluble scum layers are intolerable for waste-glass systems as they cause the glass to fail critical accelerated aging tests. Early work on sulfate solubility includes the behavior of slags and the determination of fundamental thermodynamic parameters for hightemperature systems (Beerkens 2003).

This report closely follows pioneering experimental work performed by (Holmquist 1966). Holmquist used the most current thermodynamic property values at the time of his work; these must be updated with modern values. Most subsequent studies on sulfate solubility in silicate glass cite Holmquist's groundbreaking work. Caution must be exercised when using early studies for the basis of modern efforts, as another highly cited paper (Papadopoulos 1973) was found to contain erroneous results (Harper 1973; Holmquist 1973, 1974; Papadopoulos 1974). Section 2.0 of this paper describes the gas mixing calculations and provides results with updated values from the National Institute of Standards and Technology (NIST) Joint Army-Navy-Air Force (JANAF) tables currently available on the NIST website (Chase Jr. et al. 1986). These JANAF table values may be superseded by newer, more accurate measurements as NIST deems it necessary to revise and update the tables.

To determine sulfate solubility limits, mixtures of $\mathrm{SO}_{2}, \mathrm{O}_{2}$ and $\mathrm{N}_{2}$ will be bubbled through a platinum tube into the molten glass for several hours until equilibrium is achieved. Bubbling continues for a fixed period of time or until a scum layer is observed. Scum formation indicates that the glass is saturated with $\mathrm{SO}_{3}$ and no more can be added. The equilibrium concentration of $\mathrm{SO}_{3}$ gas in contact with the glass melt is calculated from physical chemistry principles as described in the following paragraphs. It should be noted that the reactant gas concentrations expected for modern waste-glass saturation are higher than those used by Holmquist (Kot et al. 2006). The three-gas component mixture allows for better control of the equilibrium between the gaseous reactant $\left(\mathrm{SO}_{3}\right)$ and products $\left(\mathrm{SO}_{2}\right.$ and $\left.\mathrm{O}_{2}\right)$ while keeping an adequate flow rate for mixing the molten glass. The use of higher concentrations of gas in the experiment will shorten the time required to reach equilibrium (explained in detail later).

The nitrogen in the gas mix is non-reactive under these experimental conditions. It will be ignored in the Gibbs Free Energy calculation. The gas phase reaction we are concerned with is

$$
\mathrm{SO}_{3} \leftrightarrow \mathrm{SO}_{2}+1 / 2 \mathrm{O}_{2}
$$

There are many ways to write this reaction; the formula above is consistent with the approach used by Holmquist. As written, $\mathrm{SO}_{3}$ is the reactant and $\mathrm{SO}_{2}$ and $\mathrm{O}_{2}$ are the products. The Gibbs Free Energy for this reaction at a fixed temperature $\left(\Delta \mathrm{G}^{\mathrm{T}}{ }_{\mathrm{RXN}}\right)$ is calculated as

$$
\Delta \mathrm{G}_{\mathrm{RXN}}^{\mathrm{T}}=\Delta G_{S_{2}}^{T}+1 / 2 \Delta G_{O_{2}}^{T}-\Delta G_{S_{3}}^{T} .
$$


The values of $\Delta \mathrm{G}^{\mathrm{T}}$ for each reactant at a given temperature (degrees Kelvin) are obtained from the NIST JANAF tables. These tables include Gibbs Free Energy values range from $0 \mathrm{~K}$ to $6000 \mathrm{~K}$. Intermediate temperatures are interpolated as shown later.

Typical waste glasses are melted in the temperature range of $800-1300^{\circ} \mathrm{C}$. The relevant entries from the NIST JANAF database are shown in Table 1. The values of $\Delta \mathrm{G}^{\mathrm{T}}{ }_{\mathrm{RXN}}$ are calculated for each temperature using the NIST JANAF table values. Negative values of $\Delta \mathrm{G}^{\mathrm{T}}{ }_{\mathrm{RXN}}$ as seen in Table 2 indicate that the reaction products are preferred and the equilibrium will favor dissociation. A positive value indicates that the reaction will not be favored and the reactant $\left(\mathrm{SO}_{3}\right.$ in this case) will dominate in the gas phase.

Table 1: Gibbs Free Energies from NIST JANAF Tables

\begin{tabular}{|c|c|c|c|}
\hline Temperature & $\Delta G_{S_{2}}^{T}$ & $\Delta G_{O_{2}}^{T}$ & $\Delta G_{S^{\prime} O_{3}}^{T}$ \\
\hline$K$ & $\mathrm{~kJ} / \mathrm{mole}$ & $\mathrm{kJ} / \mathrm{mole}$ & $\mathrm{kJ} / \mathrm{mole}$ \\
\hline 800 & -298.37 & 0 & -321.912 \\
\hline 1000 & -296.051 & 0 & -310.258 \\
\hline 1100 & -288.725 & 0 & -293.639 \\
\hline 1200 & -281.409 & 0 & -277.069 \\
\hline 1300 & -274.102 & 0 & -260.548 \\
\hline 1400 & -266.806 & 0 & -244.073 \\
\hline 1500 & -259.518 & 0 & -227.64 \\
\hline 1600 & -252.239 & 0 & -211.247 \\
\hline & -244.967 & 0 & -194.89 \\
\hline
\end{tabular}

The reaction Gibbs Free Energy is related to the Equilibrium Constant $\left(\mathrm{K}_{\mathrm{p}}\right)$ of the reaction by Equation 3 shown below. In this equation, $\mathrm{T}$ is the temperature in Kelvin and $\mathrm{R}$ is the gas constant $\left(8.3143 \mathrm{~J} \mathrm{~K}^{-1}\right.$ mole $^{-1}$ )

$$
\log \left(\mathrm{K}_{\mathrm{p}}\right)=-\Delta \mathrm{G}_{\mathrm{RXN}}^{\mathrm{T}} /(2.303 \mathrm{RT})
$$

The $\mathrm{K}_{\mathrm{p}}$ (the equilibrium constant) is related to the partial pressures of the reactants and products by Equation 4. $\mathrm{K}_{\mathrm{p}}$ indicates how far to the right the reaction will go at a given temperature. It will indicate the relative amounts of each gas expected at a given temperature and Gibbs Free energy value. 


$$
K_{p}=\frac{P_{\mathrm{SO}_{2}} \cdot P_{\mathrm{O}_{2}}{ }^{\frac{1}{2}}}{P_{\mathrm{SO}_{3}}}
$$

The calculations are performed as follows: The values in Table 1 are used to determine $\Delta \mathrm{G}^{\mathrm{T}} \mathrm{RXN}$ using Equation 2; these values of $\Delta \mathrm{G}^{\mathrm{T}}{ }_{\mathrm{RXN}}$ are then used in Equation 3 to solve for $\mathrm{K}_{\mathrm{p}}$. In turn, $\mathrm{K}_{\mathrm{p}}$ can be used to solve for the partial pressures of the reactants or products. These results are shown in Table 2.

Table 2: The Calculated Free Energies and Equilibrium Constants for Reaction 1

\begin{tabular}{|l|l|l|l|}
\hline $\begin{array}{l}\text { Temperature } \\
(\mathrm{K})\end{array}$ & $\begin{array}{l}\Delta \mathrm{G}^{\mathrm{T}} \mathrm{RXN} \\
(\text { Joules/mole })\end{array}$ & $\log \left(\mathrm{K}_{\mathrm{p}}\right)$ & $\mathrm{K}_{\mathrm{p}}$ \\
\hline 800 & 23542 & -1.5369 & 0.0290 \\
\hline 900 & 14207 & -0.8244 & 0.1498 \\
\hline 1000 & 4914 & -0.2566 & 0.5538 \\
\hline 1100 & -4340 & 0.2061 & 1.6071 \\
\hline 1200 & -13554 & 0.5899 & 3.8894 \\
\hline 1300 & -22733 & 0.9133 & 8.1895 \\
\hline 1400 & -31878 & 1.1892 & 15.4585 \\
\hline 1500 & -40992 & 1.4272 & 26.7431 \\
\hline 1600 & -50077 & 1.6346 & 43.1074 \\
\hline
\end{tabular}

The change in sign for $\Delta \mathrm{G}^{\mathrm{T}} \mathrm{RXN}$ from positive to negative between $1000 \mathrm{~K}$ and $1100 \mathrm{~K}$ indicates that $\mathrm{SO}_{3}$ is the primary gas at lower temperatures, while at higher temperatures dissociation into the two product gases is preferred (Eq 1). This is consistent with the phase diagram that shows all three gases, in varying concentrations, from $\sim 700 \mathrm{~K}$ to $1500 \mathrm{~K}$ (Evans and Wagman 1952). The reacting gases will be $\mathrm{SO}_{2}$ and $\mathrm{O}_{2}$ in a typical experiment. Choosing them to be the "products" is a mathematical convenience.

There is a linear relationship between $\log \left(\mathrm{K}_{\mathrm{p}}\right)$ and $1 / \mathrm{T}$. The calculated Gibbs Free Energies were used to determine the equation of the linear fit. This equation (Eq 5) is used to determine intermediate values of $\mathrm{K}_{\mathrm{p}}$ not specifically listed in the NIST JANAF tables.

$$
\log \left(\mathrm{K}_{\mathrm{p}}\right)=-4756.8(1 / \mathrm{T})+4.6215
$$

Equation 4 can be rearranged to solve for $P_{\mathrm{SO}_{3}}$ or $P_{\mathrm{SO}_{2}} \cdot P_{\mathrm{O}_{2}}{ }^{\frac{1}{2}}$. The $\mathrm{K}_{\mathrm{p}}$ values calculated from Equation 3 are inserted into Equation 4 for each temperature desired. 
Holmquist used gas mixtures on the order of $95 \% \mathrm{~N}_{2}$. These melts took up to eight hours to reach equilibrium sulfate saturation. The Vitreous State Laboratory (VSL) has performed similar studies and although they do not report experimental details, it is possible to surmise the experimental conditions and gas mixes from the information offered by Holmquist and the VSL from Figure 3.1 in (Kot et al. 2006). Holmquist gives information on eight gas mixes at three temperatures. VSL performed experiments at only one temperature $\left(1150^{\circ} \mathrm{C}\right)$ and their Figure 3.1 shows $P_{\mathrm{SO}_{3}}$ ranging from 0 atm\% to $0.7 \mathrm{~atm} \%$. The resultant $\mathrm{SO}_{3}$ concentration in the glass ranges from 0 to $0.75 \mathrm{wt} \%$. Table 3 is a modified version of Holmquist's example, expanded to include gas mixes that yield concentrations of $\mathrm{P}_{\mathrm{SO}_{3}}$ comparable to those reported by VSL. The gas mixes are reported in partial pressures (same as mole fractions). The table assumes that nitrogen (or other inert gas) will be added to bring the sum of the partial pressures of the gases to 1 . The carrier gas does not participate in the chemical equilibrium with the sulfates and is present to control flow and allow for experimental control; namely allowing for a wide range of $\mathrm{SO}_{3}$ concentrations at a fixed temperature.

Table 3: Calculated Partial Pressure of $\mathrm{SO}_{3}$ at Several Temperatures at Various $\mathrm{SO}_{2}$ and $\mathrm{O}_{2}$ Partial Pressures*

\begin{tabular}{|c|c|c|c|c|c|c|}
\hline \multirow[t]{2}{*}{$P_{\mathrm{SO}_{2}}$} & \multirow[t]{2}{*}{$P_{O_{2}}$} & \multirow{2}{*}{$P_{\mathrm{SO}_{2}} \cdot P_{\mathrm{O}_{2}}{ }^{\frac{1}{2}}$} & \multicolumn{4}{|c|}{$P_{\mathrm{SO}_{3}}$} \\
\hline & & & $\begin{array}{c}1300 \mathrm{~K} \\
(1027 \mathrm{C})\end{array}$ & $\begin{array}{c}1400 \mathrm{~K} \\
(1127 \mathrm{C})\end{array}$ & $\begin{array}{c}1423 \mathrm{~K} \\
(1150 \mathrm{C})\end{array}$ & $\begin{array}{c}1500 \mathrm{~K} \\
(1227 \mathrm{C})\end{array}$ \\
\hline 0.0014 & 0.0006 & $3.43 E-05$ & 4.19E-06 & $2.22 \mathrm{E}-06$ & $1.80 \mathrm{E}-06$ & $1.28 \mathrm{E}-06$ \\
\hline 0.0024 & 0.0013 & $8.65 \mathrm{E}-05$ & $1.06 \mathrm{E}-05$ & $5.60 \mathrm{E}-06$ & $4.55 \mathrm{E}-06$ & $3.24 \mathrm{E}-06$ \\
\hline 0.0045 & 0.0029 & $2.42 \mathrm{E}-04$ & $2.96 \mathrm{E}-05$ & 1.57E-05 & $1.28 \mathrm{E}-05$ & $9.06 \mathrm{E}-06$ \\
\hline 0.0065 & 0.0035 & $3.85 E-04$ & $4.70 \mathrm{E}-05$ & $2.49 \mathrm{E}-05$ & $2.02 \mathrm{E}-05$ & $1.44 \mathrm{E}-05$ \\
\hline 0.0099 & 0.0045 & $6.64 \mathrm{E}-04$ & $8.11 \mathrm{E}-05$ & 4.30E-05 & $3.50 \mathrm{E}-05$ & $2.48 \mathrm{E}-05$ \\
\hline 0.0134 & 0.0064 & 1.07E-03 & $1.31 \mathrm{E}-04$ & $6.93 \mathrm{E}-05$ & $5.64 \mathrm{E}-05$ & 4.01E-05 \\
\hline 0.0210 & 0.0097 & $2.07 \mathrm{E}-03$ & $2.53 \mathrm{E}-04$ & $1.34 \mathrm{E}-04$ & $1.09 \mathrm{E}-04$ & 7.73E-05 \\
\hline 0.0300 & 0.0164 & $3.84 \mathrm{E}-03$ & 4.69E-04 & 2.49E-04 & $2.02 \mathrm{E}-04$ & $1.44 \mathrm{E}-04$ \\
\hline 0.0500 & 0.0250 & 7.91E-03 & $9.65 \mathrm{E}-04$ & $5.11 \mathrm{E}-04$ & $4.16 \mathrm{E}-04$ & 2.96E-04 \\
\hline 0.1000 & 0.0500 & $2.24 \mathrm{E}-02$ & $2.73 \mathrm{E}-03$ & $1.45 \mathrm{E}-03$ & $1.18 \mathrm{E}-03$ & 8.36E-04 \\
\hline 0.2000 & 0.1000 & $6.32 \mathrm{E}-02$ & 7.72E-03 & 4.09E-03 & 3.33E-03 & $2.36 \mathrm{E}-03$ \\
\hline
\end{tabular}




\begin{tabular}{|c|c|c|c|c|c|c|}
\hline \multirow[t]{2}{*}{$P_{\mathrm{SO}_{2}}$} & \multirow[t]{2}{*}{$P_{O_{2}}$} & \multirow{2}{*}{$P_{\mathrm{SO}_{2}} \cdot P_{\mathrm{O}_{2}}{ }^{\frac{1}{2}}$} & \multicolumn{4}{|c|}{$P_{\mathrm{SO}_{3}}$} \\
\hline & & & $\begin{array}{c}1300 \mathrm{~K} \\
(1027 \mathrm{C})\end{array}$ & $\begin{array}{c}1400 \mathrm{~K} \\
(1127 \mathrm{C})\end{array}$ & $\begin{array}{c}1423 \mathrm{~K} \\
(1150 \mathrm{C})\end{array}$ & $\begin{array}{c}1500 \mathrm{~K} \\
(1227 \mathrm{C})\end{array}$ \\
\hline 0.3000 & 0.1500 & $1.16 \mathrm{E}-01$ & $1.42 \mathrm{E}-02$ & $7.52 \mathrm{E}-03$ & $6.12 \mathrm{E}-03$ & $4.34 \mathrm{E}-03$ \\
\hline 0.4000 & 0.2000 & $1.79 \mathrm{E}-01$ & $2.18 \mathrm{E}-02$ & $1.16 \mathrm{E}-02$ & $9.42 \mathrm{E}-03$ & $6.69 \mathrm{E}-03$ \\
\hline 0.5000 & 0.2500 & $2.50 \mathrm{E}-01$ & $3.05 \mathrm{E}-02$ & $1.62 \mathrm{E}-02$ & $1.32 \mathrm{E}-02$ & $9.35 \mathrm{E}-03$ \\
\hline
\end{tabular}

* Partial pressures are such that $1=P_{S_{3}}+P_{S O_{2}}+P_{O_{2}}+P_{N_{2}}$

The upper parts of Table 3 correspond to calculations performed by Holmquist with modern values of the Gibbs Free Energy (up to $0.03 \mathrm{SO}_{3}$ ). Conversion of the $P_{\mathrm{SO}_{3}}$ values in Table 3 from partial pressures to percentages indicates that VSL used gas mixes composed of from $1 \%-40 \% \mathrm{SO}_{2}$. The oxygen concentration can be kept to half the $\mathrm{SO}_{2}$ concentration to yield 0 to $1 \% \mathrm{SO}_{3}$ concentrations. Holmquist noted the maximum sulfur uptake to occur at a 2:1 ratio of $\mathrm{SO}_{2}: \mathrm{O}_{2}$. Later experiments confirm this observation (Nemec and Klouzek 1998). Holmquist checked for melt saturation after 8, 16, or 24 hours with a maximum gas mix of $3 \% \mathrm{SO}_{2}$. VSL took aliquots after 3.5 hours of continuous bubbling. Their gas mixes appear to start where Holmquist's end and go up to significantly higher percentages of $\mathrm{SO}_{2}$ and $\mathrm{O}_{2}$. VSL cycled through the melting and bubbling steps from six to nine times until a significant sulfate layer appeared on the glass.

An alternative approach to this calculation is to fix the desired final $\mathrm{P}_{\mathrm{SO}_{3}}$ value, input a somewhat arbitrary partial pressure of $\mathrm{O}_{2}$ or $\mathrm{SO}_{2}$, and solve for the remaining gas. Table 3 can be used as a starting point for selecting partial pressures for one of the input gases. The span of $\mathrm{P}_{\mathrm{SO}_{3}}$ values used by VSL runs from $0 \mathrm{~atm} \%$ to $1 \mathrm{~atm} \%$, which is equivalent to 0 to 0.01 in partial pressure. Choosing a fixed starting $P_{\mathrm{SO}_{2}}$, the following equation can be used to calculate the necessary $P_{\mathrm{O}_{2}}$ to achieve the desired value of $\mathrm{P}_{\mathrm{SO}_{3}}$.

$$
P_{O_{2}}=\left(K_{p} * \frac{P_{S O_{3}}}{P_{S O_{2}}}\right)^{2}
$$

Because of the squared term, it is possible to calculate values for which the sum of $P_{\mathrm{SO}_{3}}+P_{\mathrm{SO}_{2}}+P_{\mathrm{O}_{2}}$ is greater than 1 . These results are unphysical and the desired $P_{\mathrm{SO}_{3}}$ cannot be achieved. Sums less than 1 can be mixed with nitrogen to achieve the desired $P_{\mathrm{SO}_{3}}$. Sums greater than one indicate that the Equation 6 is invalid for the given inputs at that temperature. Table 4 is a sample calculation determining the required amount of $\mathrm{O}_{2}$ needed if using a fixed partial pressure of $\mathrm{SO}_{2}$ of 0.6 (60\%) and the desired incremented $\mathrm{SO}_{3}$ concentrations using the $\mathrm{K}_{\mathrm{p}}$ value at $1150^{\circ} \mathrm{C}$. 
Table 4: Calculated Values of $P_{\mathrm{O}_{2}}$ to Generate Desired $P_{\mathrm{SO}_{3}}$ with Fixed $P_{\mathrm{SO}_{2}}$ at $1150^{\circ} \mathrm{C}$

\begin{tabular}{|c|c|c|c|}
\hline Desired $\mathrm{PSO}_{3}$ & Fixed $P_{\mathrm{SO}_{2}}$ & Calculated $\boldsymbol{P}_{\boldsymbol{O}_{2}}$ & $P_{S_{3}}+P_{S O_{2}}+P_{O_{2}}$ \\
\hline 0.0010 & 0.6000 & 0.0010 & 0.6020 \\
\hline 0.0020 & 0.6000 & 0.0040 & 0.6060 \\
\hline 0.0030 & 0.6000 & 0.0090 & 0.6120 \\
\hline 0.0040 & 0.6000 & 0.0160 & 0.6200 \\
\hline 0.0050 & 0.6000 & 0.0251 & 0.6301 \\
\hline 0.0060 & 0.6000 & 0.0361 & 0.6421 \\
\hline 0.0070 & 0.6000 & 0.0491 & 0.6561 \\
\hline 0.0080 & 0.6000 & 0.0642 & 0.6722 \\
\hline 0.0090 & 0.6000 & 0.0812 & 0.6902 \\
\hline 0.0100 & 0.6000 & 0.1003 & 0.7103 \\
\hline 0.0150 & 0.6000 & 0.2256 & 0.8406 \\
\hline $0.0200 *$ & $0.6000^{*}$ & $0.4011^{*}$ & $1.0211^{*}$ \\
\hline
\end{tabular}

* Note that the desired $\boldsymbol{P}_{\mathbf{S O}_{3}}$ is not possible as the sum of the partial pressures exceeds 1.

The method shown in Table 4 can be used to determine the gas mixtures; however, this approach challenges the accuracy of the gas mixing system as the amount of oxygen varies from $0.1 \mathrm{~atm} \%$ to $22.6 \mathrm{~atm} \%$, while the $\mathrm{SO}_{2}$ remains steady at $60 \mathrm{~atm} \%$. (Note that the highest concentration of $\mathrm{SO}_{3}$ is not achievable because it requires a gas mix with a total partial pressure greater than 1.) If specific values of $P_{\mathrm{SO}_{3}}$ are desired, then several fixed values of $\mathrm{SO}_{2}$ may be necessary to keep the $\mathrm{SO}_{2}: \mathrm{O}_{2}$ ratio reasonable and within the optimum performance range of the mass flow controllers (MFC). Varying the $\mathrm{SO}_{2}: \mathrm{O}_{2}$ ratio significantly from 2:1 will increase the time required to reach saturation as reported by Holmquist and others (Nemec and Ullrich 1998; Holmquist 1966). Table 5 shows select values of $\mathrm{SO}_{3}$ calculated for several fixed values of $\mathrm{SO}_{2}$ that span a typical experimental range with controllable partial pressures and a near 2:1 ratio of $\mathrm{SO}_{2}$ to $\mathrm{O}_{2}$. 
PNNL-23054

Table 5: Calculated $\mathrm{SO}_{3}$ Values from Controllable Mixtures

\begin{tabular}{|c|c|c|c|}
\hline Desired $\mathrm{PSO}_{3}$ & Fixed $\mathrm{PSO}_{2}$ & Calculated $\mathrm{PO}_{2}$ & $\mathrm{PSO}_{3}+\mathrm{PSO}_{2}+\mathrm{P}_{2}$ \\
\hline 0.0010 & 0.1000 & 0.0361 & 0.1371 \\
\hline 0.0020 & 0.2000 & 0.0361 & 0.2381 \\
\hline 0.0030 & 0.2000 & 0.0812 & 0.2842 \\
\hline 0.0040 & 0.2000 & 0.1444 & 0.3484 \\
\hline 0.0050 & 0.3000 & 0.1003 & 0.4053 \\
\hline 0.0060 & 0.3000 & 0.1444 & 0.4504 \\
\hline 0.0070 & 0.3000 & 0.1965 & 0.5035 \\
\hline 0.0080 & 0.4000 & 0.1444 & 0.5524 \\
\hline 0.0090 & 0.4000 & 0.1827 & 0.5917 \\
\hline 0.0100 & 0.4000 & 0.2256 & 0.6356 \\
\hline
\end{tabular}

Experimentally, complete sulfate saturation is indicated by the appearance of salt scum. The glass is then quenched and analyzed for sulfate concentration. The final sulfate concentration in the glass can be measured by x-ray fluorescence, scanning electron microscope methods, inductively coupled plasma atomic emission spectroscopy, Secondary Ion Mass Spectroscopy, Laser Ablation Mass Spectroscopy, or wet chemical assay. Several analytical methods are discussed in the literature (Ooura and Hanada 1998). 


\subsection{Test Description}

This section describes the experimental set up for sulfate solubility at PNNL. Selected glasses are heated in a specially modified furnace that is placed inside a laboratory hood to properly exhaust off-gases. The furnace was custom modified by Deltech Furnaces, Inc. (Denver, CO); the modification consists of a custom opening in the top to allow insertion of a bubble tube and observation of the melt (Figure 1).

The bubble tube is specified to be $3.18 \mathrm{~mm}$ (1/8th in.)-diameter platinum (10\% rhodium or grain growth stabilized is preferred for durability). The platinum is reported to act as a catalyst for the gas reaction (Holmquist 1966; Kot et al. 2006). A ceramic tube around the top of the platinum tube serves as a thermal insulator for handling the bubble tube and connects to the gas line via a friction fit or standard connector. To prevent molten glass from flowing into the tube, it is important that gas flows through the tube prior to its insertion into the molten glass.

The gas can be pure nitrogen (or argon) at insertion and then be switched to the reactive mixture when desired. The platinum tube is inserted into the molten glass until it touches the bottom of the crucible and then is raised to 6.35 to $12.7 \mathrm{~mm}$ ( $1 / 4$ to $1 / 2 \mathrm{in}$.) above the bottom of the crucible to prevent the bubbles from eroding the crucible. The length of the tube is not critical. It simply must be adequate for safe manipulation and gas handling. 


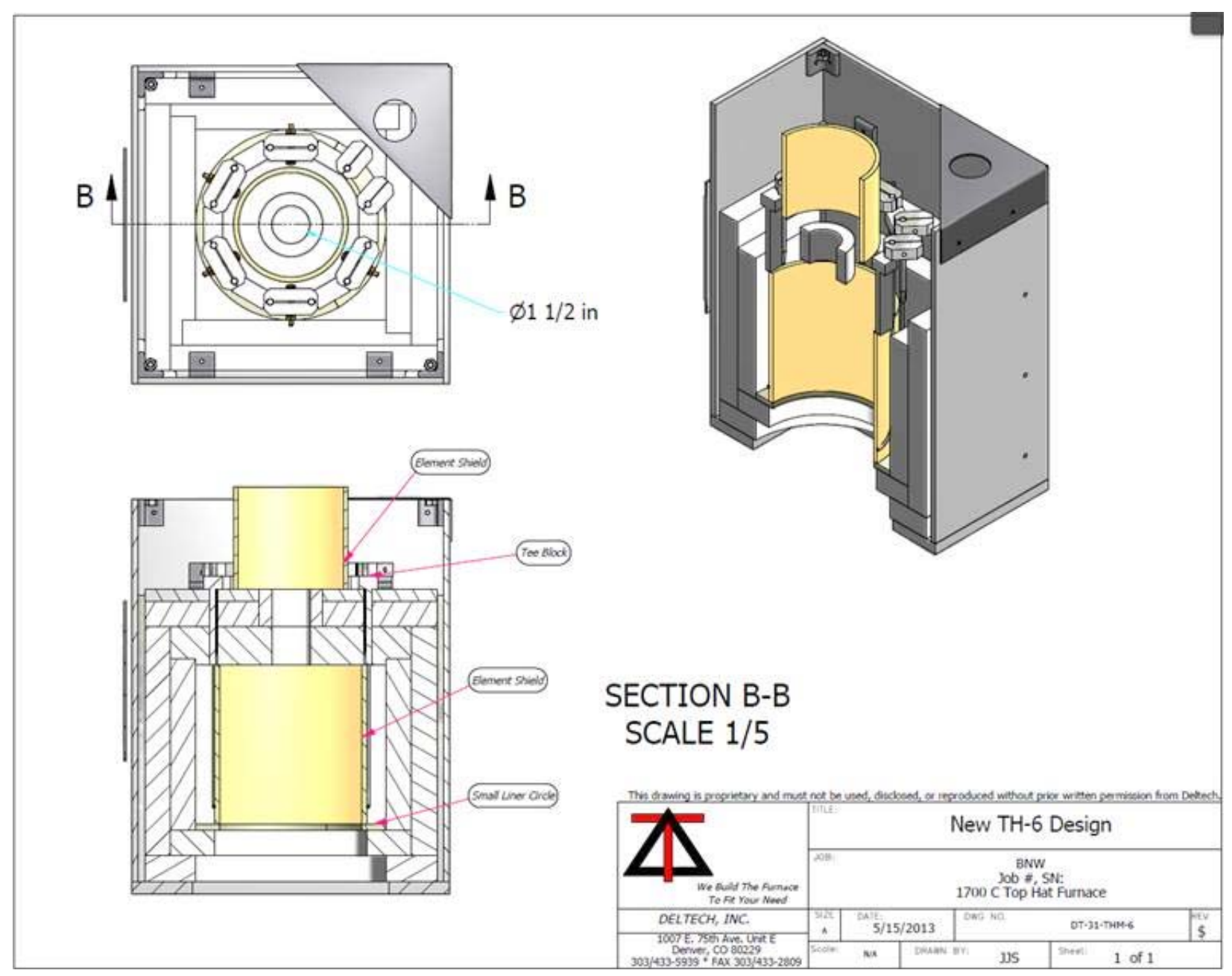

Figure 1: Modified Deltech furnace for sulfate solubility studies. This is a commercial furnace with an opening at the top for the insertion of the bubble tube. It meets all electrical safety standards.

The gas pressure is also not critical and just needs to be high enough to generate a steady flow of bubbles in the molten glass. The bubbling should be consistent and gentle. The expected flow rate for bubbling is in the range of $20-30 \mathrm{ml} \cdot \mathrm{min}^{-1}$. The flow rate should be adjusted manually based on the depth of the glass, crucible size, and bubble behavior.

The Deltech Furnace has power control thermocouples built into the heating zone. A supplemental probe thermocouple (properly calibrated) may be used near the crucible to verify the hot zone temperature. In this furnace, the probe can be inserted through the same opening as the bubble tube and has a readout that is independent from the control thermocouples. It is to be expected that there may be a slight but consistent difference between the furnace control temperatures and the actual temperature near the crucible due to heat losses through the top of the furnace, the ceramic shield around the heating elements and the bubbling.

The gas control system uses calibrated commercial parts. MFCs, calibrated by the vendor for each particular gas, are used to adjust the gas mixture. The certification documentation is kept in the project QA files. These components are certified accurate to $2 \%$ of full scale. The gases are supplied from tanks 
controlled by pressure regulators. The regulators will supply gas up to $30 \mathrm{psi}$. It should be noted that $\mathrm{SO}_{2}$ liquefies at 35 psi under room temperature conditions. Also, $\mathrm{SO}_{2}$ is toxic and proper ventilation is a key safety concern. The test gas lines have separate shutoff valves prior to the MFCs. The mixed gases are then split between the bubble tube and an exhaust by-pass to allow for better pressure and flow control. The bypass is controlled by a regulating needle valve that cannot be fully closed (Swagelok SSSVR4). The valve prevents over pressurization of the system—an OSHA requirement.

The bypass is also vented to the hood system. If the bubble tube becomes blocked, the bypass prevents over pressurization of the system and keeps the system pressure below 35 psi. Flow through the system is designed so that the by-pass valve controls the bubble rate.

The MFCs are electrically connected to a MKS 247 D four-channel control system, which can be set locally or by remote computer control as described in the user manual (MKS Instruments, MKS Type 247D Four-Channel Readout, 120714-P1, Rev. A 7/97). The user manual indicates that only certain types of cable can be used with the control box and MFCs. Substituting other cables may result in mixing errors. The piping schematic is shown in Error! Reference source not found.. Table 6 lists the parts specifications. All tubing is $6.35 \mathrm{~mm}(1 / 4 \mathrm{in}$.) O.D. welded 316L stainless steel. Thin-walled stainless steel flexible tubing connects to the ceramic thermal insulation tube around the bubble tube. 


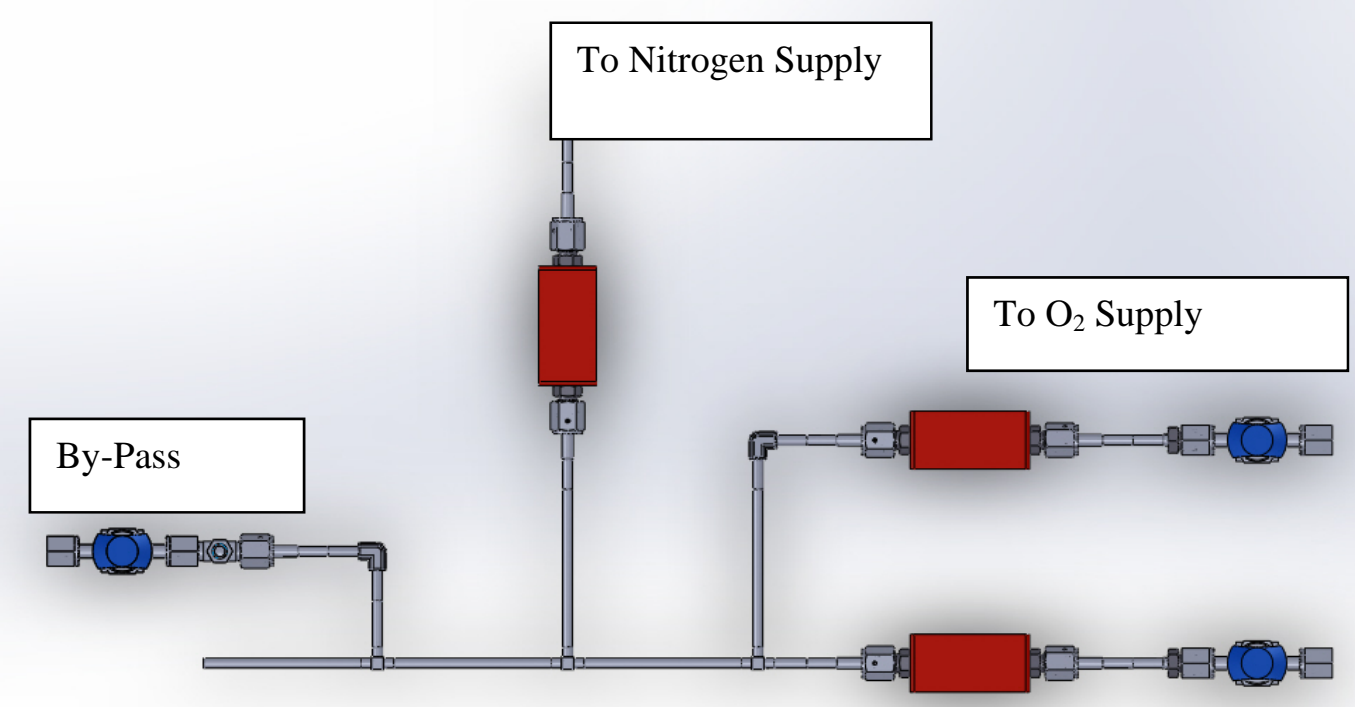

To Furnace

To $\mathrm{SO}_{2}$ Supply

Figure 2: Schematic of the gas mixing system. The MFCs are represented in red, valves in blue. The reactant gases precede the inert nitrogen in the piping. The by-pass valve is adjusted to control the bubbling rate but is designed never to be fully closed which keeps the system from over pressurizing. The MFCs are electrically connected to a MKS 247D gas controller.

Table 6: Parts List and Specifications for Gas Mixing System

\begin{tabular}{|c|c|c|c|}
\hline Parameter & $\mathrm{SO}_{2}$ & $\mathrm{O}_{2}$ & $\mathrm{~N}_{2}$ \\
\hline Input Pressure & $30 \mathrm{psi}$ & $30 \mathrm{psi}$ & $30 \mathrm{psi}$ \\
\hline MFC Maximum Flow & $10 \mathrm{sccm}$ & $10 \mathrm{sccm}$ & $30 \mathrm{sccm}$ \\
\hline Initial MFC Flow & $5 \mathrm{sccm}$ & $5 \mathrm{sccm}$ & $20 \mathrm{sccm}$ \\
\hline
\end{tabular}




\subsection{Safety Hazards}

The two major safety concerns are handling the pure oxygen gas, which can initiate combustion, and handling pure $\mathrm{SO}_{2}$ gas, as it is toxic. The mixed gases should be exhausted to appropriate hood systems. Water should be kept out of the gas mixing system, as it will induce corrosion in the stainless steel components. Care must be taken to keep the system flowing and to maintain the pressure under 35 psi. $\mathrm{SO}_{2}$ becomes a liquid at pressures over $35 \mathrm{psi}$. The tubing and components of the gas mixing system can be severely damaged by liquid $\mathrm{SO}_{2}$. The MFCs are designed to handle gases only and cannot be considered usable if liquid enters them. The injection of liquid into the molten glass could cause an explosion from the rapid expansion of the liquid into gas when the hot glass is contacted.

Glass melting is a high-temperature process and caution must be used. The melting furnace must be in good repair and used according to the manufacturer's design, or it can present significant electrical and heat hazards. The furnace should also be inspected electrically and physically for flaws before each use. 


\subsection{Typical_Instructions}

These are the typical steps to perform sulfate saturation. A specific test plan may modify or repeat these instructions.

1. Select glass batch or cullet for testing

2. Record the glass identifier in the laboratory record book (LRB)

3. Determine the mass of batch or cullet for testing

4. Record the mass in the LRB

5. Select an appropriate crucible for the size of the batch or cullet. The molten material should not exceed $75 \%$ of the crucible volume.

6. Note crucible size and any identifiers in the LRB

7. Weigh the empty, clean crucible and bubble tube

8. Record the weights in the LRB

9. Weigh the crucible with batch or cullet

10. Record the total weight in the LRB

11. Load the crucible into the furnace. The furnace may be preheated or cool. Generally, raw batch is loaded into a cool furnace; cullet can be loaded into a hot furnace.

12. Record in the LRB whether the furnace was preheated or not. The heating ramp rate and soak temperature should also be recorded in the LRB.

13. Select the furnace temperature for the experiment

14. Record the temperature in the LRB

15. Monitor the temperature at or near the crucible with a thermocouple or optical pyrometer. Note any difference in temperature between the furnace control setting and the crucible temperature. Adjust power to the furnace as necessary.

16. Record any significant changes in temperature or furnace power in the LRB. Note the time of the occurrence

17. Wait for the crucible to reach a constant temperature and molten state

18. Note the time in the LRB and the appearance of the glass

19. Connect the bubble tube to the gas mixing system

20. Set the bypass valve to fully open position and then open the upstream valves as needed

21. Turn on the gas flow by setting all the cylinder regulators to $30 \mathrm{psi}$

22. Set the mass flow controller to allow nitrogen to flow through the system

23. Use the control box to adjust the gas mixture

24. Open the valves to the $\mathrm{SO}_{2}$ and $\mathrm{O}_{2}$ MFCs

25. Begin gas flow through the bubble tube by closing the by-pass valve

26. Adjust the flow rate so that the bubbling is gentle and does not cause splashing or overflow

27. Lower bubble tube into the molten glass 
28. Touch the bubble tube to the bottom of the crucible, if possible, and then raise it $1 / 4$ to $1 / 2$ inch (6.35 to $12.7 \mathrm{~mm})$

29. Record the time and temperature of the crucible and furnace. Bubbling may cool the glass.

30. Record any changes in the appearance of the glass with bubbling

31. Continue to bubble for a prescribed amount of time

32. Remove the bubble tube while the gas is flowing. Wait for glass to drip from the bubble tube and ensure that the tube is not blocked with glass.

33. Turn off gas flows, starting with the valves before the MFCs for the $\mathrm{O}_{2}$ and $\mathrm{SO}_{2}$. Then close the cylinder regulators. Next close the nitrogen cylinder regulator. This will allow the reactive gas to leave the piping to the exhaust. Close the bypass valve last to keep the system clean after allowing pure nitrogen to run through the system.

34. Remove crucible and quench or cool the glass as prescribed. (This may precede step 33.)

35. Weigh together the bubble tube, crucible, and any poured glass to determine loss on ignition

36. Place the glass in a marked container and reserve for chemical analysis

37. Record all relevant times, temperatures and gas mixture in the LRB 


\subsection{References}

Beerkens, RGC. 2003. "Sulfate Decomposition and Sodium Oxide Activity in Soda-Lime-Silica Glass Melts." Journal of the American Ceramic Society 86(11):1893-99. 10.1111/j.1151-2916.2003.tb03578.x.

Chase Jr., MW, CA Davies, JR Downey Jr., DJ Frurip, RA McDonald, and AN Syverud. 1986. NISTJANAF Thermochemical Tables 1985. Accessed on October 1, 2013 at http://kinetics.nist.gov/janaf/ (last updated 2000).

Evans, WH, and DD Wagman. 1952. "Thermodynamics of Some Simple Sulfur-Containing Molecules." Journal of Research of the National Bureau of Standards 49(3):141-48. 10.6028/jres.049.015.

Harper, TJ. 1973. "Comments on 'the Solubility of $\mathrm{SO}_{3}$ in Soda-Lime-Silica Melts'." Physics and Chemistry of Glasses 18(4):letters.

Holmquist, S. 1973. "Comments on 'the Solubility of $\mathrm{SO}_{3}$ in Soda-Lime-Silica Melts'." Physics and Chemistry of Glasses 18(4):letters.

Holmquist, S. 1966. "Oxygen Ion Activity and Solubility of Sulfur Trioxide in Sodium Silicate Melts." Journal of the American Ceramic Society 49(9):467-\&. 10.1111/j.1151-2916.1966.tb13301.x.

Holmquist, S. 1974. "Reaction Models for Sulfate in Glass." Physics and Chemistry of Glasses 18(4):letters.

Kot, WK, H Gan, Z Feng, and IL Pegg. 2006. Final Report: Sulfate Solutbility in RPP-WTP HLW Glasses. Report No. VSL-06R6780-1, Vitreous State Laboratory, The Catholic University of America, Washington, D.C.

Nemec, L, and J Klouzek. 1998. "Interaction of Gas Mixtures Containing So2 and O-2 with Glass Liquids." Journal of Non-Crystalline Solids 231(1-2):152-60. 10.1016/s0022-3093(98)00414-1.

Nemec, L, and J Ullrich. 1998. "Calculations of Interactions of Gas Bubbles with Glass Liquids Containing Sulphates." Journal of Non-Crystalline Solids 238(1-2):98-114. 10.1016/s00223093(98)00682-6.

Ooura, M, and T Hanada. 1998. "Compositional Dependence of Solubility of Sulphate in Silicate Glasses." Glass Technology 39(2):68-73.

Papadopoulos, K. 1974. "Reply to Comments by T.J. Harper and S. Holmquist on 'the Solubility of $\mathrm{SO}_{3}$ in Soda-Lime-Silica Melts' by K. Papadopoulos." Physics and Chemistry of Glasses 18(4):letters.

Papadopoulos, K. 1973. "The Solubility of $\mathrm{SO}_{3}$ in Soda-Lime-Silica Melts." Physics and Chemistry of Glasses 14(3):60-65. 



\section{Appendix A}

Figure 3.1 from Kot 2006

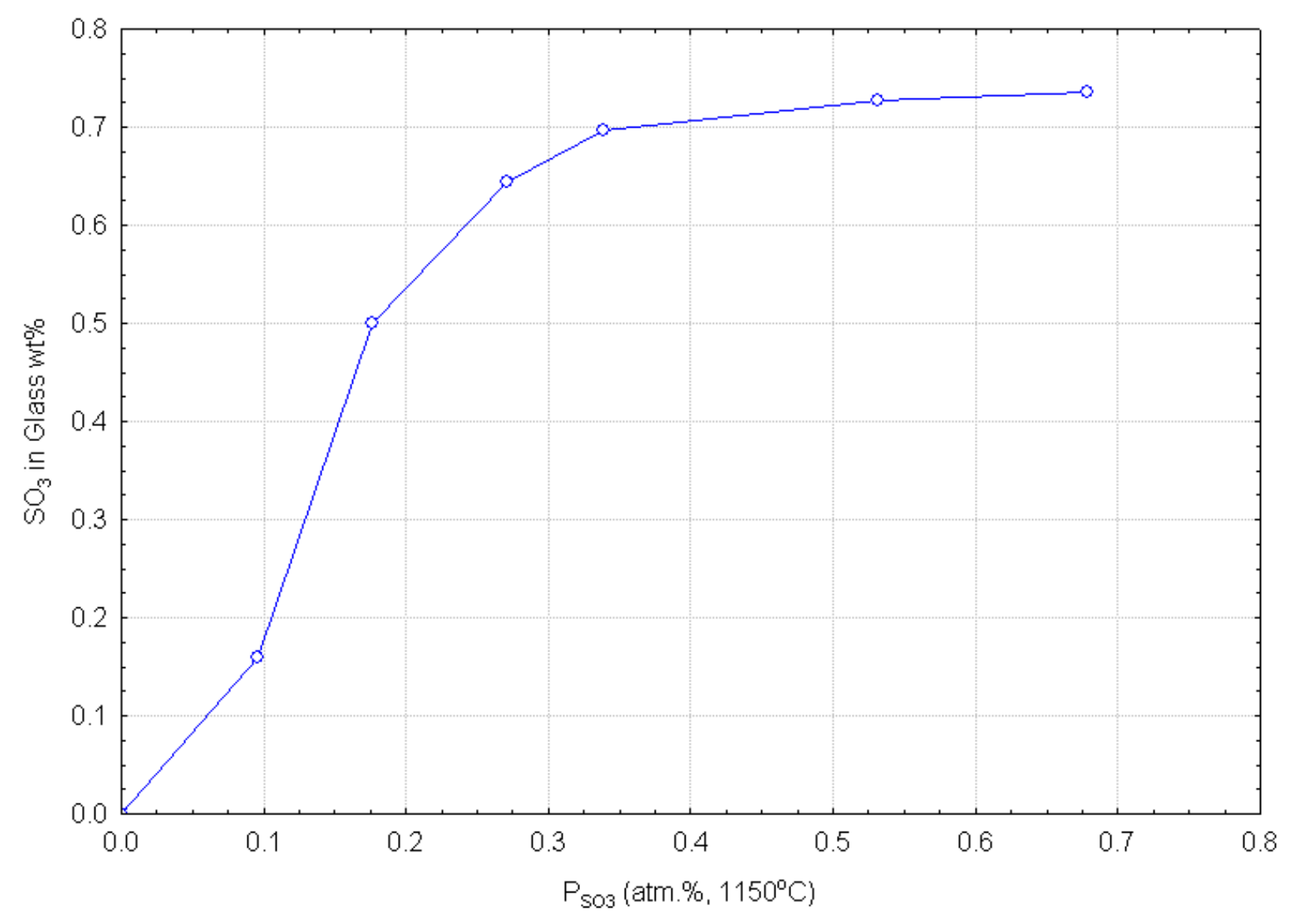





\section{Distribution}

No. of

\section{$\underline{\text { Copies }}$}

\# Name

Organization

Address

City, State and ZIP Code

\# Organization

Address

City, State and ZIP Code

Name

Name

Name

Name

Name (\#)

\# Name

Organization

Address

City, State and ZIP Code

No. of

\section{$\underline{\text { Copies }}$}




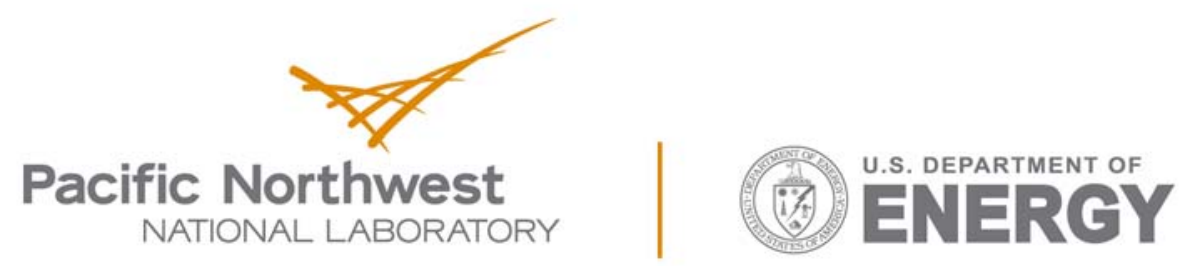

Proudly Operated by Battelle Since 1965

902 Battelle Boulevard

P.O. Box 999

Richland, WA 99352

1-888-375-PNNL (7665)

www.pnnl.gov 